\title{
A BLINDAGEM DISCURSIVA DAS MORTES CAUSADAS PELO AMIANTO NO BRASIL: CRIMINOLOGIA CRÍTICA E DANO SOCIAL
}

\section{${ }^{1}$ Marília de Nardin Budó}

\section{RESUMO}

A limitação do sistema de controle penal à perseguição dos crimes de rua, denunciada pela criminologia crítica, exige uma definição autônoma de seu objeto, alcançando os danos sociais dos Estados e mercados. O objetivo deste trabalho é identificar o tratamento do caso do amianto no Brasil e no mundo, no que tange ao conflito discursivo que oculta sua identificação como causador de incontáveis mortes. Analisa-se, através do método dialético, a apropriação do discurso médico pelo Legislativo e pelo Judiciário. Do contraponto das interpretações percebe-se a tentativa de uma blindagem, que ultrapassa a ciência para a conservação dos interesses do capital.

Palavras-chave: Criminologia crítica, Dano social, Amianto, Crimes dos poderosos

\section{EL BLINDAJE DISCURSIVO DE LAS MUERTES CAUSADAS POR EL AMIANTO EM BRASIL: CRIMINOLOGÍA CRÍTICA Y DAÑO SOCIAL}

\section{RESUMEN}

La limitación del sistema de control penal a la persecución de los crímenes callejeros exige una definición autónoma del objeto de la Criminología, alcanzando los daños sociales. El objetivo del trabajo es identificar el tratamiento del caso del amianto en Brasil y en el mundo, en lo que afecta al conflicto discursivo que oculta las incontables muertes que causa. Analiza, a través del método dialéctico, la apropiación del discurso médico por el Legislativo y por el Judiciario. Del contrapunto de las interpretaciones percibe-se la tentativa de un blindaje, que ultrapasa la ciencia para la conservación de los intereses del capital.

Palabras-claves: Criminología crítica, Daño social, Amianto, Crímenes de los poderosos

\footnotetext{
1 Doutora pela Universidade Federal do Paraná - UFPR, Paraná (Brasil). Professora pela Fundação Meridional - IMED, Paraná (Brasil). E-mail: mariliadb@yahoo.com.br
} 


\section{INTRODUÇÃO}

Toda ação violadora dos direitos humanos possui a chance de provocar uma reação negativa ou positiva da comunidade. $\mathrm{O}$ que determina que se encaminhe para uma ou outra não é a gravidade do dano causado às pessoas e ao meio ambiente, mas sim a forma como a história dessas violações é contada, a forma como ela, por fim, é percebida pela comunidade.

A partir dessas ponderações, este trabalho tem o objetivo de desafiar, inicialmente, os limites epistemológicos tradicionalmente atribuídos à criminologia para encontrá-los muito além da ação do sistema de controle penal. Dessa maneira, será possível trazer para o âmbito da criminologia um objeto costumeiramente deixado de lado, sobretudo na literatura criminológica brasileira: os danos sociais gerados pelo capitalismo, em geral, e pelas corporações, em conluio com os Estados, em especial. O caso do amianto no Brasil é o foco da apreciação da temática. A pergunta que orienta o trabalho questiona quais são as estratégias discursivas utilizadas para blindar os graves danos à saúde e ao meio ambiente causados pela extração, industrialização e comercialização do amianto, de maneira a permitir a sua manutenção legal, por um lado, e a desresponsabilização do Estado e dos mercados frente a eles.

Para responder ao questionamento, em um primeiro momento apresenta-se o marco teórico, centrado na crítica da criminologia tradicional como legitimadora dos crimes massivos e na necessidade de uma alteração dos limites epistemológicos dessa disciplina para alcançá-los. Em um segundo momento, é apresentado o caso do amianto no Brasil e no mundo, sobretudo em relação às regulações nacionais e internacionais, e sua interpetação judicial e política no Brasil. A análise é realidade através do método dialético, considerando a realidade social a partir de suas contradições. São estudados documentos referentes às audiências públicas realizadas no Congresso nacional e no STF, bem como a literatura nacional e internacional dedicada à temática.

\section{CRIMES INVISÍVEIS E DANO SOCIAL: ESTADOS E MERCADOS}

Para além da ruptura de paradigma que caracterizou a criminologia dos anos 1960 e 1970, garantindo a passagem do paradigma etiológico ao paradigma da reação social (ANDRADE, 2003), outras problemáticas podem ser pontuadas como objetos da epistemologia criminológica na atualidade. A despeito da tentativa de autonomização da 
criminologia em relação ao direito penal, proporcionada pela sua nova posição como crítica externa à atuação do sistema de controle, o fato é que o objeto da criminologia se manteve em grande medida limitado ao conceito jurídico-dogmático de crime. Neste tópico, buscar-se-á verificar se há necessidade de superação desses limites de maneira a atingir como objeto de estudo os danos sociais mais graves causados pelos poderosos.

\subsection{Dos Crimes de Colarinho Branco aos Crimes dos Poderosos: Precisões Terminológicas}

Apesar de não ter sido o primeiro estudioso a romper com essa ideologia, já que E. A. Ross havia realizado estudo semelhante no ano de 1908, foi o estudo seminal de Edwin Sutherland que efetivamente impactou a academia na sua demonstração de que efetivamente pessoas provenientes de classes sociais altas cometem crimes (FRIEDRICHS, 2015). O principal dilema consistia na definição dessas condutas danosas como crimes, tendo em vista sua invisibilidade na operacionalização do sistema penal. Para caracterizar um crime de colarinho branco, os seus elementos chaves seriam: o criminoso ser pertencente às classes altas, ou uma pessoa de colarinho branco, o crime ser cometido no curso de sua ocupação e o crime ser uma violação da confiança (SUTHERLAND, 1940).

As análises marxistas ligadas à criminologia, sobretudo no âmbito da criminologia crítica nos anos 1970, de início questionaram essa perspectiva do crime como um dado a ser estudado pelos criminólogos. A percepção de que o direito penal não é neutro, mas sim serve aos interesses das classes dominantes auxiliou na reconfiguração do objeto de estudo da criminologia, que se transportou do sujeito criminoso aos mecanismos de construção social da criminalidade, e seus efeitos (SANTOS, 1991). As análises realizadas nessa época buscaram empreender um novo olhar sobre o crime e o controle do crime, desviando-o dos pobres para encontrá-lo na estrutura social.

O termo "crimes dos poderosos" é mais recente, e vem, dentro da criminologia crítica, sobretudo a partir de meados dos anos 1980, como uma categoria específica dentro daquela mais ampla do "colarinho branco" (FRIEDRICHS, 2015)1. Os crimes dos poderosos

\footnotetext{
${ }^{1}$ Segundo Friedrichs, o fato de Sutherland não ter se debruçado o suficiente sobre o conceito de "crime de colarinho branco" fez com que o termo esteja sendo utilizado para casos bastante diferentes, como, por exemplo, em relação a pessoas que não detêm poder econômico e político, mas praticam condutas, como empregados, de quem o detém. A solução proposta por Friedrichs é a de considerar o termo "White-collar crime" como um termo amplo que inclui diferentes tipos de crimes, dentro do qual estariam inseridos como principais tipos o "corporate crime" e o "occupational crime". Enquanto os "corporate offenders" seriam intrinsecamente poderosos, os occupational offenders variariam desde os relativamente poderosos aos totalmente destituídos de poder, como os empregados das corporações. Assim, apesar de o termo "White-collar crime" ser utilizado em
} 
atentam a ações e práticas que reconhecidamente violam os direitos de grupos de pessoas ou causam danos a trabalhadores, consumidores, comunidades e/ou ao meio ambiente (BARAK; LEIGHTON; COTTON, 2015). Uma de suas características mais desafiadoras é o caráter praticamente invisível à maior parte das pessoas, por serem raramente referidos e discutidos sob esse enfoque pelos meios de comunicação e mesmo na academia e na política.

\begin{abstract}
Quando eles são cobertos e discutidos, se não são francamente negados, são tipicamente desculpados, justificados e/ou neutralizados, chegando ao ponto de serem vistos, ao final, como "não exatamente crimes". Esses "não-crimes", cometidos pelos poderosos, podem incluir crimes corporativos, crimes de colarinho branco organizacionais, crimes de Estados e crimes estatais-corporativos. [...] Esses crimes podem incluir ações cometidas contra trabalhadores, locais de mercado, contribuintes, sistemas políticos, o ar que respiramos, assim como crimes contra a humanidade, como os atos de tortura, genocídio ou terrorismo de Estado (BARAK; LEIGHTON; COTTON, 2015, p. 63-64).
\end{abstract}

Barak (2015, p. 4) explica que, diante da maneira como a economia e a política dialetizam nessa área, o estudo dos crimes dos poderosos tem sido classificado em sete campos de atividades: 1) crimes da globalização; 2) crimes corporativos; 3) crimes ambientais; 4) crimes financeiros; 5) crimes estatais; 6) crimes estatais-corporativos; 7) crimes rotinizados do Estado. A principal característica unificadora dessas categorias é que lidam com importantes influências, sendo protegidas pelo aparato de controle da criminalidade do Estado capitalista.

Isso significa que esse ramo da criminologia crítica também não tem como sucumbir às ilusões do sistema penal: não se trata de um punitivismo de esquerda (KARAM, 1996) que, ao buscar denunciar a criminalidade dos poderosos, acaba legitimando a ação do sistema penal que é estruturalmente montado para funcionar a serviço do capital ${ }^{2}$. Isso seria uma contradição (ALVESALO; TOMBS, 2002). Assim, ao colocar o dano social no centro dos objetos de análise está-se, antes de qualquer outra coisa, denunciando as próprias organizações políticas e econômicas vigentes, nas esferas local, nacional e global, sem cuja superação não é possível imaginar mudanças no insustentável desenvolvimento do capital e em todas as vitimizações que o acompanham (BARAK, 2015, p. 33).

\title{
1.2 Do crime ao dano: a superação dos limites epistemológicos da criminologia
}

algumas situações para designar crimes dos poderosos, o certo é que os dois termos não são sinônimos (FRIEDRICHS, 2015, p. 43).

${ }^{2}$ Como nota Karam, os punitivistas de esquerda "não percebem que, quando chega a haver alguma punição relacionada com fatos desta natureza, esta acaba recaindo sobre personagens subalternos, assim, sem maiores perdas, podendo o sistema penal cumprir aquele seu papel instrumentalizador da manutenção e reprodução dos mecanismos de dominação" (KARAM, 1997, p. 75). 
A definição de crime a que a criminologia historicamente se submeteu fez com que, por causa dessa limitação, "[...] a afirmação de que a guerra imperialista e o racismo são crimes não é somente considerada uma injustificável imposição de valores, mas, também, um uso incompetente da noção de crime" (SCHWENDINGER, H.; SCHWENDINGER, J., 1980, p. 118). Daí que pensar o caráter criminoso dos sistemas é fundamental para se pensar uma superação dessas grandes violações de direitos humanos. Schwendinger e Schwendinger (1980) refletiram sobre isso ainda em 1975, afirmando que, enquanto os criminólogos não repensarem o conceito de crime, sobretudo para superar sua definição legalista, eles seguirão sendo defensores da ordem e não guardiães dos direitos humanos.

A forma como a criminologia esteve, historicamente, atrelada ao direito penal e à atuação do sistema de controle fez com que também ela acabasse se ocupando fortemente em perseguir o ladrão e ignorar o genocídio, nas palavras de Bernal et al. (2014). A pergunta mais fundamental nesse ponto é aquela realizada por Morrison: onde esteve a criminologia enquanto se produziam os crimes massivos de Estado que ocorreram desde meados do século XIX até nossos dias? Que papel cumpriu a o discurso da criminologia, como discurso da modernidade, nos grandes massacres que a história nos apresenta como parte do "processo civilizador"? (MORRISON, 2006).

Zaffaroni (2007) irá mostrar que a criminologia estava lá em muitos desses genocídios. No colonialista, por exemplo, a criminologia positivista estava para legitimar a ação dos colonizadores com base na inferioridade biológica de indígenas e africanos. A ciência estava presente como discurso a garantir não apenas que os crimes de estado ficassem impunes como também para que as condutas das vítimas do genocídio fossem ainda criminalizadas, muitas delas quase ou nada danosas (ZAFFARONI, 2007).

Se o que se pretende é contribuir a evitar esses crimes, é óbvio que a criminologia deve se ocupar dos discursos que os fomentam mediante o refinamento de técnicas de neutralização e, por consequência, deve ser objeto de estudo da criminologia o comportamento dos teorizadores que fabricam esses discursos, e de quem os defende pelos meios massivos (ZAFFARONI, 2007, p. 33).

São muitos os discursos que servem à manutenção das relações de poder, perpassando a justificação da opressão. Como observa Muncie, já nos anos 1980 os abolicionistas haviam exposto que, se a preocupação dos criminólogos com o crime reside na busca por estabilidade social, segurança pessoal e justiça social, então possivelmente seria necessário olhar para além do "crime", para descobrir onde as maiores ameaças e riscos à pessoa e à propriedade efetivamente residem (MUNCIE, 1999).

A tentativa de superação desses limites já é possível de ser encontrada na definição de crime de colarinho branco, de Sutherland. Para ele, seria possível inserir nesse conceito 
não somente as violações à lei penal, mas também as violações ao direito civil e ao direito administrativo, em razão de que a produção legislativa sofre grande influência da classe praticante desse tipo de delito (FRIEDRICHS, 2015). Essa seria uma maneira de garantir que a criminologia alcançasse aqueles atores sociais poderosos que conseguem prevenir que a etiqueta "crime" seja aplicada à ampla gama de atividades danosas a que se dedicam (FRIEDRICHS, 2015, p. 43).

O fato de reconhecer a definição de crime como a atribuição de uma etiqueta estruturalmente orientada pelo sistema penal capitalista a encontrar sempre os sujeitos mais vulneráveis por condutas menos danosas não permite negar a existência de ações socialmente negativas, definidas, por Baratta (2002, p. 218), como a "negação ou a repressão de necessidades reais, entendendo necessidade real como a faculdade de existir e desenvolver a própria existência, que os indivíduos possuem em função da evolução das capacidades de produção material e cultural, em uma sociedade dada".

Também Hulsman (1989) busca escapar da definição de crime para dar à criminologia outro objeto: as situações problemáticas, ou problemas que, antes de garantirem a seus atores uma punição centralizada e formalizada, permitiriam a busca pelo enfrentamento dos problemas, a partir do aprendizado, do crescimento e da não alienação das vítimas.

A tentativa de superação da criminologia para o enfoque do dano não implica em uma negação da própria disciplina enquanto tática, mas na percepção de que qualquer luta que se possa fazer dentro da criminologia será absolutamente limitada (HILLYARD; TOMBS, 2013). Para Hillyard e Tombs (2013, p. 184), em termos estratégicos, garantir o enfoque do dano implica na possibilidade de ir além desses limites. Partindo do pressuposto de que os danos mais graves não se encontram na definição de crime, a definição de dano abarcaria as atividades de Estado e de corporações, que são prejudiciais às pessoas, seja pela falta de condições de vida, a violação de direitos humanos, incluindo uma gama de danos que afetam a muitas pessoas ao longo de seu ciclo vital (HILLYARD; TOMBS, 2013, p. 184). O conceito de dano encoraja concepções de vitimização como ubíquas, garantindo o reconhecimento de suas formas mais danosas para além daquelas comumente reconhecidas pela mídia, pelo direito e pelo Estado (MUNCIE, 1999).

É claro, por outro lado, que, se a intenção não é a de promover um punitivismo de esquerda, o aumento dos limites do objeto de estudo da criminologia não leva consigo a

aplicação ou a tentativa de aplicação do direito penal, dada a necessária preservação do princípio de legalidade e, evidentemente, os critérios de um direito penal mínimo devem ser respeitados (NATALI, 2015). 


\title{
2 As mortes silenciadas dos trabalhadores do amianto: risco conhecido, dano ignorado
}

\begin{abstract}
Nas lembranças de Romana, uma a sobressalta. Ela e Mario levando a então pequena Maria Rosa para passear nos arredores da fábrica onde o pai era um trabalhador orgulhoso. Redemoinhos de pó se levantavam do material descartado, era até bonito. E então Maria Rosa, já adulta e mãe de um filho, aparece na casa da mãe: "Estou com mesotelioma" (BRUM, 2014).
\end{abstract}

$\mathrm{Na}$ busca por compreender danos sociais grandiosos e de magnitude potencialmente inestimável, como no caso das doenças provocadas pelo amianto, este tópico trata, inicialmente, sobre as questões médicas, políticas e econômicas envolvendo o uso dessa fibra no Brasil e no mundo hoje. Em seguida, parte para a discussão da relação entre a sua extração, industrialização e comercialização, e o discurso justificador de sua manutenção no Brasil sobretudo nos âmbitos do Legislativo e do Judiciário.

\subsection{O amianto: aspectos médicos, políticos e econômicos}

No campo da medicina, não são poucos os estudos que, há pelo menos um século, vêm comprovando a relação direta entre a exposição do ser humano às fibras do amianto e diversas doenças, sendo as mais citadas a asbestose - fibrose pulmonar - e o mesotelioma um tipo de câncer de pulmão (MENDES, 2001) .

A primeira pesquisa a ser publicada relacionando o contato com o asbesto à fibrose pulmonar data de 1907, tendo sido realizada pelo médico inglês H. Montagne Murray (MENDES, 2001). Já a pesquisa que comprovou definitivamente a relação do asbesto com o câncer de pulmão é de 1955, realizada pelo médico também inglês Richard Doll, apesar de vários outros estudos desde a década de 1930 já apontarem para essa possibilidade

\footnotetext{
${ }^{3} \mathrm{O}$ amianto, ou asbesto, é um mineral extraído em minas e que facilmente se separa em fibras. Seu uso principal na atualidade se dá na construção civil. No Brasil, 95\% do uso do amianto ocorre na construção civil, principalmente na produção de telhas de fibrocimento, mas a matéria-prima também é utilizada em vários outros produtos (FIESP, 2009). Um estudo produzido pela FGV a pedido da FIESP revela que a cadeia do amianto no Brasil se inicia na mineração, em Minaçu, Goiás. Cerca de $70 \%$ do amianto extraído no Brasil é utilizado pelo mercado interno, o que contrasta com o maior produtor mundial, o Canadá, onde $98 \%$ da mineração é destinada à exportação (RUFF, 2008). Em termos industriais, são onze as empresas que fabricam produtos com base de amianto no Brasil. Segundo a pesquisa da FGV, apenas uma das empresas produtoras de fibrocimento no país não utiliza amianto, a Brasilit, do grupo Saint-Gobain. Os produtos que utilizam o fibrocimento no Brasil são, principalmente, as telhas e painéis, as chapas onduladas e outros artigos, como caixas d'água (FIESP, 2009).
}

(MENDES, 2001).

Apesar de a industrialização brasileira ser bastante retardatária se comparada à Europa e aos Estados Unidos, desde 1956 há documentação científica sobre casos de 
asbestose no país. Um artigo bastante interessante é o sugestivamente intitulado "Asbestose no Brasil: Um Risco Ignorado", redigido por Nogueira et al., em 1975. No texto, os autores atentam para o fato de que provavelmente os casos de doenças relacionadas ao amianto estivessem passando despercebidos nos diagnósticos clínicos, sobretudo, de doenças pulmonares (NOGUEIRA, 1975).

Em razão dos danos comprovados à saúde do trabalhador, ao meio ambiente e à saúde pública, o amianto vem sendo banido pouco a pouco no mundo todo, sendo hoje já oficialmente proibido em mais de sessenta países, como já o foi em toda a União Europeia, em 2005, e em alguns países latino-americanos, como a Argentina, o Uruguai e o Chile.

Organizações internacionais, como a Organização Mundial da Saúde (OMS) e a Organização Internacional do Trabalho (OIT), também estão há anos mobilizadas para a eliminação das doenças causadas pelo asbesto, ambas recomendando os Estados a banirem de seus territórios o mineral em quaisquer atividades. No caso da OMS, em 2006 foi editado um documento em que, além de identificar a relação do mineral com vários tipos de câncer e outras doenças, recomenda claramente o seu banimento (WHO, 2006) ${ }^{4}$.

No âmbito da OIT, a Convenção $\mathrm{n}^{\mathrm{o}}$ 162, sobre a Utilização do Asbesto com Segurança, de 1986, surgiu como forma de responder às pressões mundiais pela regulação da questão do amianto (ILO, 1986). A Convenção foi internalizada no Brasil através do Decreto executivo $n^{\circ} 126$, de 22 de maio de 1991. Nela, a OIT recomenda a substituição do amianto ${ }^{5}$ e de produtos que contenham o amianto por outros materiais ou produtos, e a proibição total ou parcial do uso do amianto ou produtos que contenham amianto. Contudo, trata-se apenas de uma recomendação, cuja exceção aparece na própria convenção, o que a torna bastante fraca em termos de pressão política nos setores fabris. No caso da não proibição, algumas medidas preventivas são indicadas.

Essa possibilidade de um uso controlado seguro do amianto passou a ser defendida na década de 1980, baseada, sobretudo, na diferenciação, por uma parte da literatura médica,

4 Exposure to asbestos, including chrysotile, causes cancer of the lung, larynx and ovaries, and also mesothelioma (a cancer of the pleural and peritoneal linings). Asbestos exposure is also responsible for other diseases such as asbestosis (fibrosis of the lungs), and plaques, thickening and effusion in the pleura (WHO, 2006).

${ }^{5} \mathrm{Na}$ Convenção, "o termo amianto refere-se à forma fibrosa dos silicatos minerais que pertencem às rochas metamórficas do grupo das serpentinas, ou seja a crisotila (amianto branco), e do grupo das anfíbolas, isto é, a actinolita, a amosita (amianto azul), a tremolita, ou todo composto que contenha um ou mais desses elementos minerais" (ILO, 1986).

dos danos causados por dois tipos de asbestos: a crisotila, ou amianto branco, e o anfibólio, ou amianto azul. A "hipótese dos anfibólios" - amphibole hypothesis -, como ficou conhecida, postula que "(1) os mesoteliomas observados entre trabalhadores expostos ao asbesto crisotila 
podem ser explicados pela sua mistura com o asbesto anfibólio, e (2) a crisotila possui uma potencialidade carcinogênica menor do que os anfibólios" (STAYNER; DANKOVIC; LEMEN, 1996). Essa hipótese, contudo, foi desmoralizada no campo médico a partir de estudos que comprovaram que ela não possui evidências que a sustentem. Mesmo regiões onde a crisotila é declarada pura ou, pelo menos, predominante, possuem um elevado diagnóstico de casos de mesoteliomas, como, por exemplo, o caso já bastante conhecido da cidade de Casale Monferrato, na Itália (MAGNANI et al., 1995).

Tendo em vista que a crisotila corresponde a $95 \%$ da produção de amianto no mundo, com essa tese, o mercado do amianto praticamente não sofreria qualquer tipo de alteração. Fica evidenciado, assim, o caráter financeiramente interessante à indústria do amianto nesse tipo de estudos, desresponsabilizando-se das fortes acusações.

A Convenção 162 da OIT, neles baseada, alcançou, como nota Mendes, “[...] a dupla façanha de proibir a extração, exportação, industrialização e utilização dos asbestos-anfibólios (amosita, crocidolita, tremolita, antofilita, etc.)”, que na época já estavam banidos na maioria dos países, protegendo-se, contudo, a crisotila, "[...] atribuindo-lhe suposta inocuidade de efeitos deletérios à saúde e à vida, quando utilizada em condições ditas "seguras" (MENDES, 2001, p. 21). Não é de se estranhar a rapidez com a qual a referida convenção foi ratificada pelo Brasil e incorporada ao ordenamento jurídico deste país, que se encontra entre os cinco maiores produtores da crisotila no mundo. Estrategicamente, o fato de ter sido a OIT a declarar a possibilidade do seu uso controlado tornou praticamente blindado o mercado da crisotila. Para Mendes, isso evidenciou uma política de defesa da crisotila no Brasil, que pode ser exemplificada também pela Lei 9055, de 1995 e pelo Decreto 2350 de 1997, que proibiram o amianto anfibólio, mas considerou a crisotila passível de extração, industrialização, utilização e comercialização (MENDES, 2001, p. 23).

Ademais dessa blindagem realizada à crisotila, outro elemento fundamental a ser discutido e superado é o fato de que o reconhecimento de seus potenciais danos à saúde estaria ligado à exposição meramente ocupacional (MENDES, 2001, p. 23). Contudo, há comprovações de que, além de não haver um limite seguro de exposição do trabalhador a esse material, tampouco se pode afirmar que o risco se limite à ocupação. Há estudos que comprovam o aparecimento de asbestose em crianças filhas de pais trabalhadores na indústria do amianto, além de casos de famílias inteiras que desenvolveram o câncer do amianto, o mesotelioma (MAGNANI et al., 1995). No Brasil, desde a extração da matéria-prima, passando pelo transporte, que pode levar ao contato do produto com a população, daí ao processo produtivo, ao novo transporte e finalmente no consumo, é evidente que a exposição se dá na comunidade além dos trabalhadores de todos os setores citados. Contudo, o caso do 
amianto não está sendo efetivamente tratado como questão de saúde pública no Brasil (CASTRO; GIANNASI; NOVELLO, 2003, p. 906).

Quanto ao impacto ambiental, as próprias características do mineral demonstram o grave problema de seu descarte: em razão de sua indestrutibilidade pelos meios tradicionais, não há hoje uma alternativa para a não contaminação ambiental pelo amianto, por exemplo, nas demolições de casas e prédios que acabem liberando o pó da fibra. As palavras que designam este mineral - asbesto, na origem grega; amianto, na origem latina - significam, respectivamente, incombustível e incorruptível (GIANNASI, 1995).

Em razão do banimento do amianto em grande parte dos países que eram antes os consumidores internacionais, vem ocorrendo a tentativa de blindagem discursiva e política da substância nos países marginais. Como observa Castleman (1995), a prática já usual de migração dos perigos industriais dos países centrais para os marginais se aplica também ao caso do amianto. Para o autor, além da migração da utilização da substância, material ou produto perigoso, também está havendo a exportação da forma de pensar o perigo, sobretudo na forma do discurso sobre limites seguros de exposição a substâncias tóxicas. Trata-se, portanto, da exportação de um discurso pseudo-científico formado por partes interessadas, principalmente por cientistas financiados pela indústria internacional do amianto.

Para Castleman (1995), dois problemas graves cercam essa ideologia do uso controlado do asbesto. $\mathrm{O}$ primeiro é o que diz respeito à construção internacional dos limites de exposição que garantam a segurança dos expostos, que é realizada com a assinatura de cientistas muitas vezes financiados ou mesmo assalariados de empresas do ramo do amianto. O segundo é a existência de standards duplos (double standards): as mesmas companhias multinacionais operam com uma determinada ordem de critérios de segurança nos Estados Unidos e com outra, mais flexível, na África do Sul, na Índia ou mesmo no Brasil. Trata-se de uma realidade reportada inclusive pela OIT, ainda em $1984^{6}$.

A respeito da cientificidade das posições tomadas pela OIT e pela OMS, além de outros órgãos, há numerosos trabalhos e reportagens mostrando a filiação financeira de

\footnotetext{
${ }^{6}$ No texto, o autor reporta nove casos de Double Standards envolvendo a indústria do amianto no mundo, tendo como vítimas os trabalhadores e consumidores de países como Brasil, Índia, Coreia do Sul e África do Sul (CASTLEMAN, 1995).
}

cientistas à indústria do amianto ${ }^{7}$. São vários os históricos de cientistas que eram considerados uma ameaça à indústria do amianto nas décadas de 1960 e 1970 e se tornaram seus aliados na década de 1990 (McCULLOCH; TWEEDALE, 2008). Um dos cientistas mais conhecidos no campo da defesa da crisotila é o físico David Bernstein, autor de numerosos trabalhos 
financiados pela indústria do amianto $^{8}$. A despeito de seu reconhecido comprometimento ético com o setor, e não por coincidência após ter admitido também ser financiado pela indústria brasileira, por pelo menos duas vezes o cientista esteve no Brasil para depor sobre o a questão do amianto em audiências públicas. Em 1999, Bernstein depôs na audiência pública relativa ao PL 2.186/96, defendendo a já referida hipótese dos anfibólios. Em 2012, em relação à Ação Direta de Inconstitucionalidade (ADIN) nº 3937/SP, esteve em audiência pública no Supremo Tribunal Federal (STF), apresentado como "PHD em medicina e toxicologia ambiental pelo Instituto de Medicina Ambiental da Universidade de Nova Iorque".

Na contramão da tendência mundial de banimento do asbesto, que favorece a saúde pública e o meio ambiente, o Brasil segue o caminho do uso controlado do mineral, favorecendo apenas os mercados. É o que se depreende de todas as normativas referentes ao tema no país. No anexo II do Decreto 3048 de 1999, o amianto aparece dentre os agentes patogênicos causadores de doenças profissionais ou do trabalho. No mesmo decreto, na Lista A, o amianto é relacionado a dez tipos de doenças. Todas elas seguem a referida convenção 162 da OIT, acreditando na diferenciação entre os dois tipos de asbestos e na possibilidade de produção livre de riscos à saúde humana'.

\footnotetext{
${ }^{7}$ Vários deles são citados no relatório Exporting Harm. Cf. Ruff (2008).

${ }^{8}$ No ano de 2007, ele foi indicado pela Georgia Pacific, indústria de produtos contendo crisotila proveniente da mina Union Carbide, na Califórnia, como testemunha em um processo no qual a empresa figurava como ré diante de uma vítima do amianto. Em seu interrogatório, após uma exposição inicial onde defendeu sua tese a respeito da ausência de riscos na manipulação controlada da crisotila, o advogado da vítima questionou se ele recebia financiamento da indústria do amianto. Ele respondeu que sim, tendo indicado o valor aproximado que recebeu. Além disso, demonstra que o estudo realizado sobre o amianto brasileiro foi bancado pela SAMA, do grupo Eternit. Por fim, ainda respondeu "sim, está correta", à afirmação do advogado sobre a ausência de aceitação no campo científico de suas conclusões a respeito da inofensividade da crisotila (RUFF, 2008).

${ }^{9}$ Em 01 de julho de 2014, o Ministério do Trabalho publicou a Nota Técnica 141, na qual obriga as empresas que comercializam produtos de fibrocimento que contêm amianto/asbesto a cumprirem todas as instruções contidas no Anexo 12 da NR 15 sobre atividades e operações insalubres (BRASIL, 1991). Em resumo, a nota técnica esclarece que, em acordo à Lei 9055/95 e à Convenção 162 da OIT, cabe, por exemplo, às lojas de materiais de construção garantir a avaliação ambiental de poeira de asbesto pelo menos a cada seis meses, além de exames médicos após término do contrato de trabalho ou da exposição, por no mínimo 30 anos. Também obriga a todas as demais normas, como o vestiário duplo, os chuveiros, além da realização de exames pulmonares anuais em todos os empregados (BRASIL, 2014). Para buscar a suspensão dessa nota técnica, o Instituto Brasileiro de Crisotila, OSCIP que defende o setor produtor do amianto no Brasil, entrou com ação ordinária na Justiça Federal. Perdeu a liminar e até o mês de agosto de 2015 o processo estava concluso para julgamento (O processo pode ser consultado no site da Justiça Federal da primeira região sob o número 0084962-82.2014.4.01.3400). Pelo teor da decisão que indeferiu a medida liminar já ficou claro ao IBC que por
} 
No nível estadual, são cinco os estados que baniram o amianto, sendo que duas leis estaduais foram declaradas inconstitucionais, pelo STF, em razão de um argumento formal de invasão da competência da União ${ }^{10}$. As demais estão sendo discutidas em outras Ações Diretas de Inconstitucionalidade (ADI) e Ações de Descumprimento de Preceito Fundamental (ADPF) no $\mathrm{STF}^{11}$. Ressalte-se, contudo, que o STF está em vias de mudar seu entendimento para discutir o direito à saúde acima das questões formais de competência (BORGES; FERNANDES, 2014), o que pode ser visualizado na convocação de audiência pública no bojo da ADI 3937/SP, realizada em 2012. Diante de tantas controvérsias, a Associação Nacional dos Magistrados do Trabalho (ANAMATRA) ingressou com ADI para declarar inconstitucional o artigo $2^{\circ}$ da lei $9055 / 95$ que permite a extração, industrialização e comercialização do amianto crisotila, em face dos riscos comprovados à saúde humana ${ }^{12}$.

A polêmica não é diferente no âmbito do Poder Legislativo. Não são poucas as denúncias de comprometimento político de parlamentares, em virtude de financiamento de campanha, de se venderem ao lobby do amianto, sobretudo no que tange à mineração realizada pela Eternit, poderosa multinacional, no Estado de Goiás. No ano de 2000 uma Comissão Especial na Câmara dos Deputados foi criada para apreciar o Projeto de Lei $\mathrm{n}^{\circ}$ 2.186/96, que dispunha, em seu texto original, sobre o progressivo banimento do amianto no Brasil. Em artigo analisando a atuação da Comissão, Carlos Eduardo Soares de Freitas, João Paulo Cunha e Dr. Rosinha demonstram serem três os principais argumentos pró-amianto que preponderam no Legislativo brasileiro: o discurso político-nacionalista, o discurso econômico e o discurso acadêmico-científico. O primeiro se centra na necessidade de defesa da crisotila como produto brasileiro em detrimento de outros produtos de origem estrangeira. O mais irônico nesse tópico, é a denúncia que o deputado Caiado faz do interesse econômico internacional do banimento do amianto no Brasil, acusando todos os movimentos próbanimento do amianto de serem vendidos à indústria dos materiais alternativos, em uma grande teoria da conspiração. $O$ argumento econômico se debruça sobre a importância econômica para a região de Goiás em termos de empregos, arrecadação de tributos etc. Já o terceiro, se centra em uma pesquisa realizada pelo professor e doutor Ericson Bagatin, da Universidade de Campinas (Unicamp), que teve seu estudo financiado pelo setor do amianto

essa via será difícil obter a suspensão da nota. Em razão disso, forte pressão foi realizada diretamente perante o Ministério do Trabalho e Emprego, o que se pode verificar na inserção do tema na pauta da reunião da rodada da Comissão Tripartite Paritária Permanente - CTPP, realizada nos dias 1 e 2 de setembro de 2015. Na reunião, porém, o assunto acabou não entrando para o debate e, de qualquer maneira, a CTPP não teria poderes para deliberar sobre o tema (OLIVEIRA, 2015).

${ }^{10}$ ADI 2656/SP; ADI 2396/MS.

${ }^{11}$ ADI 3937/SP; ADI 3356/PE; ADI 3357/RS; ADI 3406/RJ; ADI 3470/RJ; ADPF 234/SP.

${ }^{12}$ ADI 4066. 
no Brasil, conforme declaração dele próprio em audiência pública (FREITAS; CUNHA; DR. ROSINHA, s/d).

O relatório dessa Comissão Especial, contudo, foi completamente desviado para os interesses econômicos, ficando completamente de lado todos os achados a respeito dos malefícios do amianto à saúde, em grande medida baseado nos estudos de Bagatin e outros cientistas internacionais reconhecidamente bancados pela indústria (BRASIL, 2001).

Em 2010, a Comissão de Meio Ambiente e Desenvolvimento Sustentável divulgou o Dossiê Amianto Brasil (BRASIL, 2010), um trabalho de dois anos representado em quase 700 páginas, em sentido oposto ao parecer da Comissão especial de 2001. As conclusões do dossiê, que detalhou a situação ambiental, trabalhista e de saúde pública, foi pelo banimento do amianto no país. O que mais chama a atenção é o fato de que a comissão é bastante heterogênea, presentes deputados dos mais variados partidos e posições no espectro político. O dossiê, contudo, não trouxe maiores repercussões. Apesar de haver vários projetos de lei buscando banir o amianto no Brasil, percebe-se que pela via do Parlamento será difícil que efetivamente o debate progrida para o âmbito da saúde pública e supere tanto a dimensão exclusivamente econômica quanto a pseudo-ciência que a legitima.

\subsection{A exposição ao amianto e a responsabilidade dos Estados e dos mercados}

De tudo o que foi exposto acerca da realidade política, econômica e científica sobre a extração, a industrialização e a comercialização do amianto, nota-se a existência de riscos reais elevados da exposição ao amianto, e mortos e doentes ainda não adequadamente representados, dada a ausência de uma adequada anamnese, em alguns casos, e dada a efetiva venda dos serviços médicos às empresas, em outros. A total invisibilidade dos riscos, apesar de eles serem conhecidos há pelo menos cem anos no mundo e sessenta anos no Brasil revelam a ausência de interesse do Estado e dos mercados na ação de prevenção.

A principal argumentação do setor industriário na manutenção da utilização do amianto é o do impacto da proibição nos custos da produção, tendo em vista a necessidade de substituição de equipamentos na linha de produção, bem como de formação de mão-de-obra qualificada, dado o fato de o processo de produção ser mais complexo do que o do fibrocimento com amianto. Como se vê, um argumento que duplamente busca desresponsabilizar o setor: primeiro, porque opta pelo dano à vida de terceiros em detrimento de seus próprios danos econômicos, como se a escolha não estivesse em suas mãos; segundo, porque oculta o fato de os estudos sobre os riscos do asbesto serem antigos o suficiente para 
os interessados economicamente nesse ramo já terem pensado em alternativas, ao invés de seguirem negando-os. Na luta em torno da possibilidade de proibição encontra-se a sociedade civil, muito bem representada por grupos como a Associação Brasileira dos Expostos ao Amianto (ABEA, 2015).

Como notam McCulloch e Tweedale (2008), a história da saúde ocupacional na indústria do asbesto foi marcada por três crises: asbestose (1920s), câncer relacionado ao asbesto (1940s), e mesotelioma (1960s). Nesse sentido, a indústria foi uma vítima, mas sua reação nunca foi a de uma parte lesionada e vulnerável. Durante cada crise, a indústria foi capaz de organizar estratégias e defesas que foram se tornando mais sofisticadas à medida que as evidências contra o amianto iam também crescendo.

Para Ruggiero, não é difícil encontrar discursos justificadores para os crimes dos poderosos, sobretudo na história do liberalismo, como se houvesse uma aura sagrada conferida ao livre mercado. O individualismo é, de fato, da ordem do liberalismo e do livre mercado, o que em si justifica a desnecessidade de pensar o coletivo (RUGGIERO, 2015, p. 63). A necessidade de suprir a lógica do capital se liga à necessidade de tolerância perante esses crimes, dentro da noção de utilidade, que torna a sua coerção desnecessária. Como observa Ruggiero (2015), os criminosos de sucesso são aqueles que apresentam a si próprios como filantropos, que garantem que suas imagens não fiquem ligadas a um rótulo de criminosos, mas sim que apareceram como pessoas que beneficiam aos outros ${ }^{13}$.

Um exemplo bastante recorrente no que tange aos crimes dos poderosos é a fala tocante à geração de empregos que determinada atividade reconhecida e comprovadamente danosa ao ambiente e às pessoas proporciona (RUGGIERO, 2015, p. 64). Da mesma forma, a ideia Smithiana de que a acumulação das riquezas nas mãos de alguns e com base nos interesses individuais é necessária para sua futura distribuição pode auxiliar a justificar os crimes dos poderosos.

Além disso, Ruggiero observa que, de acordo com o pensamento a respeito da liberdade de John Stuart Mill, outra justificação pode ser encontrada: o desaparecimento das vítimas ocorre no exato momento em que elas são transformadas em vítimas consentidas. Se uma determinada empresa, por exemplo, adverte o consumidor ou o trabalhador de um determinado risco e o deixa livre para escolher se irá ou não correr o risco, então sua

\footnotetext{
${ }^{13}$ No caso do amianto, a operação de greenwashing realizada em torno da figura de Stephan Schmidheiny é um excelente exemplo do que refere Ruggiero. De proprietário da Eternit, empresa de amianto que causou e ainda vem causando - dado o caráter de longo prazo do câncer do amianto - mortes de famílias inteiras na Itália e em outros países, passou a ser reconhecido como ambientalista, e foi convidado a participar do Rio +20 (IL GREEN, 2014).
} 
responsabilidade enquanto empresa de tornar o ambiente livre desse risco desaparece, e a escolha de ser uma vítima passa a ser dela própria (RUGGIERO, 2015).

Nesse contexto, a indústria do amianto, no Brasil e no mundo é sim responsável pelas mortes causadas e merecem receber sobre si todo o peso que a informação sobre essa danosidade social gigantesca proporciona. Trata-se de uma violência organizacional (GREEN; SHOU, 2015, p. 60), baseada em decisões que sabidamente geram danos a seres humanos, tendo na sua base a violência estrutural, dada pela repressão das necessidades humanas fundamentais, típica de países de elevada desigualdade social (BARATTA, 1993).

Por outro lado, cabe também resgatar o papel dos cientistas e das universidades nessa luta, que é luta de classes: não são poucos os (des)serviços que cientistas renomados, financiados pelas empresas do amianto têm realizado para garantir a manutenção do status quo judicial e legislativo no que tange ao banimento do amianto. No mundo todo essa tem sido uma luta contínua, com as firmas usando informações de seus próprios institutos de pesquisa "independentes", somadas à pressão política para influenciar os governos para relaxar o controle do uso do amianto (REIMAN, 2007, p. 86).

Como observa Ruggiero, os danos causados por condutas corporativas inseridas na lógica do mercado selvagem mostram que os crimes dos poderosos vão além das regulações que as tornam legais ou ilegais: um tipo de crime do poder é justamente o de insistir em práticas danosas inspiradas nos valores cardeais das economias de mercado. Ele próprio intitula o artigo referindo-se a uma frase atribuída a um político norte-americano: "It's the economy, stupid!" (RUGGIERO, 2007). O conceito de externalidade, proveniente da economia auxilia nessa análise: “externalidade designa o efeito de uma transação sobre uma terceira parte que não consentiu com, ou desempenhou qualquer papel na realização dessa operação" (RUGGIERO, 2015). Trata-se de um conceito que deu um poderoso ímpeto na percepção do dano econômico como um dano colateral.

Ademais de todo esse escrutínio, que pode deixar claro o quanto o poder econômico, aliado ao poder político garantem a persistência da permissão do risco aos trabalhadores e todas as pessoas expostas ao amianto no Brasil, o problema é maior: a ciência, comprada como foi, a Justiça, negligente e formalista, em nenhum deles os trabalhadores do amianto podem confiar. De fato, quem está fazendo história na luta por um mundo livre de amianto não é o poder, é o contrapoder. São os grupos da sociedade civil, que, organizados com outra ciência e com outra política têm conseguido algumas conquistas fundamentais.

Como notam McCulloch e Tweedale, a ciência nunca é suficiente para resolver os problemas de saúde ocupacional, e - acrescenta-se - os problemas ambientais. No que tange 
ao amianto, não é possível afirmar que falta informação, ou que não existem estudos conclusivos. O que falta são garantias políticas e sociais para habilitar esse conhecimento a ser usado para o benefício da saúde e do meio ambiente. "Sem essas salvaguardas, os dados podem ser disputados ou inventados, e a avaliação do risco manipulada para vantagens comerciais ou políticas" (McCULLOCH; TWEEDALE, 2008, p. 275). Historicamente, e o saber criminológico tradicional demonstra isso, a ciência tem sido usada contra os pobres e vulneráveis, a favor dos poderosos. Assim, é somente nas mãos dos atingidos, daqueles realmente afetados com as mortes de seus pais, filhos e outros amores que essas informações podem surtir um efeito transformador (McCULLOCH; TWEEDALE, 2008). Sem ultrapassar o sistema econômico totalmente criminoso que domina a realidade atual, serão essas e outras histórias de sofrimento e morte contadas por várias gerações.

\section{CONCLUSÃO}

A invisibilidade dos danos sociais causados pelos mercados em conluio com os Estados é uma característica dominante quando analisada a forma como tanto o sistema de justiça quanto a criminologia se preocupam com os crimes de rua e não com aquelas condutas que efetivamente provocam as mortes e desastres mais dolorosos para as comunidades. Diante disso, cabe à criminologia crítica, com seu objetivo transformador e crítico do capitalismo e das condições de reprodução social das desigualdades que o próprio sistema de justiça criminal efetiva, trazer a lume a danosidade social das condutas dos poderosos.

O caso do amianto no Brasil e no mundo é um exemplo poderoso de total negligência diante de uma danosidade comprovada, de mortes documentadas, de ambientes completamente poluídos. E, no entanto, ciência, mercado e Estado se reúnem, em uma política internacional de migração dos danos ao mundo periférico, para blindar as informações e possíveis práticas de banimento do amianto.

Diante da necessidade de silenciar esses danos e construir estratégias de desresponsabilização, verificou-se, a partir dos documentos analisados e da bibliografia, que são várias as estratégias discursivas utilizadas para tanto: a justificação econômica da geração de empregos e da negação da vitimização pelo consenso; a justificação "pseudo"-científica comprada pela indústria de que é possível o manuseio de risco controlado; a compra de médicos garantindo a sub-representação dos números de mortes causadas pelo amianto; a ausência quase total de notícias na grande mídia sobre os malefícios do amianto; o lobby da indústria no Poder Legislativo; e, finalmente, a total inércia e o formalismo do Judiciário 
frente a todas as evidências mundiais que depõem contra o amianto.

A visibilização dessas vítimas, o empoderamento discursivo e político dos grupos atingidos, organizados localmente e em redes são fundamentais passos a serem trilhados na busca por alternativas. $\mathrm{O}$ olhar científico da criminologia pode contribuir nesse campo na tentativa de visualização dos danos como atos que mostram ser o capitalismo ele próprio criminogênico. A busca desenfreada pelos lucros, a ausência total de ética, a falácia da responsabilidade social e do marketing ecológico, discursos de propaganda rasa para legitimar o extermínio das pessoas mais vulneráveis econômica e politicamente, devem ser exploradas e tornadas visíveis num mundo onde qualquer transformação efetiva deve provir das bases.

\section{REFERÊNCIAS}

ALVESALO, Anne; TOMBS, Steve. Working for criminalization of economic offending: contradictions for critical criminology? Critical criminology, 2002, n. 11. p. 21-40.

ANDRADE, Vera Regina Pereira de. A ilusão de segurança jurídica: do controle da violência à violência do controle penal. Porto Alegre: Livraria do Advogado, 2003.

ASSOCIAÇÃO BRASILEIRA DE EXPOSTOS AO AMIANTO. Quem somos. Disponível em: <www.abrae.com.br>. Acesso em 20 jan. 2015.

BARAK, Gregg. On the visibility and neutralization of the crimes of the powerful and their victims. In: (ed.). The Routledge International Handbook of the Crimes of the

Powerful. New York: Routledge, 2015.

BARAK, Gregg; LEIGHTON, Paul; COTTON, Allison. Class, Race, Gender \& Crime: The social realities of Justice in America. $4^{\text {th }}$ ed. Lanham: Rowman \& Littlefield, 2015.

BARATTA, Alessandro. Criminologia crítica e crítica do direito penal. Rio de Janeiro: Revan, 2002.

BARATTA, Alessandro. Direitos Humanos: entre a violência estrutural e a violência penal. Fascículos de Ciências Penais. Porto Alegre, vol. 6, n. 2, p. 44-61, abril-junho, 1993.

BERNAL, Camilo Ernesto; CABEZAS, Sebastián; FORERO, Alejandro; RIVERA, Iñaki; VIDAL, Iván. Un debate epistemológico sobre el daño social, los crímenes internacionales y los delitos de los mercados. In: RIVERA, Iñaki (Coord..). Delitos de los Estados, de los Mercados y daño social. Barcelona: Anthropos, 2014.

BORGES, Heloísa Bot; FERNANDES, Valdir. O uso do amianto no Brasil: o embate entre duas racionalidades no Supremo Tribunal Federal. Ambiente \& Sociedade, São Paulo, v. XVII, n. 2. p. 175-194, abr.-jun. 2014. 
BRASIL, Câmara dos Deputados. Parecer da Comissão de comissão especial destinada a apreciar o Projeto de Lei no 2186/1996. Brasília, 2001. Relator: Ronaldo Caiado. Disponível em:

<http://www.camara.gov.br/proposicoesWeb/prop_mostrarintegra?codteor=25154\&filename =Parecer-PL218696-26-09-2001>. Acesso em: 21 mai. 2015.

BRASIL. Câmara dos Deputados. Dossiê Amianto Brasil: relatório do Grupo de Trabalho da Comissão de Desenvolvimento Sustentável da Câmara dos Deputados destinado à análise das

Implicações do uso do amianto no Brasil. Relator: Edson Duarte. Brasília: 2010. Disponível em: <http://www.camara.gov.br/sileg/integras/769516.pdf>. Acesso em: 25 mar. 2015.

BRASIL. Decreto No 3.048, de 6 de maio de 1999. Aprova o Regulamento da Previdência Social, e dá outras providências. Disponível em: <http://www2.camara.leg.br/legin/fed/decret/1999/decreto-3048-6-maio-1999-368532normaatualizada-pe.html>. Acesso em: 01 mar. 2015.

BRASIL. Ministério do Trabalho e Emprego. Nota Técnica $n^{\circ}$ 141. Aplica-se o Anexo 12 da Norma Regulamentadora $\mathrm{n}^{\circ} 15$ às empresas que comercializam produtos de fibrocimento que contêm amianto/asbesto. Brasílis, 2014.

BRASIL. Ministério do Trabalho e Emprego. NR 15 - Atividades e Operações Insalubres. Anexo n. ${ }^{\circ}$ 12: Limites de tolerância para poeiras minerais. Brasília, 1991. Disponível em: <http://portal.mte.gov.br/data/files/FF8080812BE914E6012BEF43234B23D6/nr_15_anexo1 2.pdf>. Acesso em: 20 jul. 2015.

BRASIL. Supremo Tribunal Federal. ADI 3937/SP. Audiência pública. Disponível em: $<$ http://www.stf.jus.br/arquivo/cms/ProcessosAudienciasPublicasAcoesAmianto/anexo/Trans cricoes_Audiencia_sobre_Amianto_Texto_consolidado.pdf $>$. Acesso em: 20 mai. 2015.

BRUM, Eliane. Romana e o bilionário do amianto: a dor que não prescreve. Coluna. El país, 24 nov. 2014. Disponível em:

<http://brasil.elpais.com/brasil/2014/11/24/opinion/1416832282_033103 .html>. Acesso em: 25 nov. 2014.

CASTLEMAN, Barry I. The Migration of Industrial Hazards. International Journal of Occupational and Environmental Health. Philadelphia, PA, v.1, n. 2, Apr-Jun 1995. p. 8596.

CASTRO, Hermano; GIANNASI, Fernanda; NOVELLO, Cyro. A luta pelo banimento do amianto nas Américas: uma questão de saúde pública. Ciência e Saúde Coletiva, v. 8, n. 4, p. 903-911, 2003. 
FEDERAÇÃO DAS INDÚSTRIAS DO ESTADO DE SÃO PAULO. O papel dos produtos de amianto na cadeia da construção civil: dimensão econômica efeitos concorrenciais. São Paulo: FIESP, 2009

FREITAS, Carlos Eduardo de; CUNHA, João Paulo; DR. ROSINHA. Amianto e política no Brasil: avaliando a Comissão Especial da Câmara dos Deputados. Disponível em: <http://www.abrea.com.br/Freitas.pdf>. Acesso em: 20 ago. 2015.

FRIEDRICHS, David O. Crimes of the powerful and the definition of crime. In: BARAK, Gregg (ed.). The Routledge International Handbook of the Crimes of the Powerful. New York: Routledge, 2015. p. 39-49.

GIANNASI, Fernanda. O uso do amianto no Brasil: um grande desafio. Cad. CRH., Salvador, n. 23. p.128-140, jul/dez.1995.

GREEN, Gary S.; SHOU, Huisheng. Operationalizing organizational violence. In: BARAK, Gregg (ed.). The Routledge International Handbook of the Crimes of the Powerful. New York: Routledge, 2015. p. 50-61.

HILLYARD, Paddy; TOMBS, Steve. ¿Más allá de la criminología? Revista Crítica Penal y Poder, Barcelona, 2013, n. 4, p. 184.

HULSMAN, Louk. Criminología crítica y concepto de delito. In: Abolicionismo Penal. Buenos Aires: Ediar, 1989.

IL GREEN washing internazionale di mr Eternit. Disponível em:

<http://www.valori.it/speciali/il-green-washing-internazionale-mr-eternit-5258.html>. Acesso em: 20 jun. 2014.

INTERNATIONAL LABOUR ORGANIZATION. Asbestos Convention, 1986 (n. 162).

Disponível

em:<http://www.ilo.org/dyn/normlex/en/f?p=NORMLEXPUB:12100:0::NO::P12100_ILO_C ODE:C162>. Acesso em> 15 mai.2015.

KARAM, Maria Lúcia. Utopia transformadora e abolição do sistema penal. In: PASSETTI, Edson; SILVA, Roberto B. Dias da. Conversações abolicionistas: uma crítica do sistema penal e da sociedade punitiva. São Paulo: IBCCRIM, 1997. p. 67-84.

KARAM, Maria Lúcia. A esquerda punitiva. Discursos sediciosos: crime, direito e sociedade, ano 1, n. 1, 1996. p. 79-92.

MAGNANI et al. Pleural maligant mesotelhioma and non-ocupational exposure to asbestos in Casale Monferato, Italy. Occupational and Environmental Medicine, 1995, n. 52. p. 362367. Disponível em: <http://www.ncbi.nlm.nih.gov/pmc/articles/PMC1128238/pdf/oenvmed00066-0002.pdf>. Acesso em: 20 mai. 2015. 
McCULLOCH, Jock; TWEEDALE, Geoffrey. Defending the indefensible: The Global Asbestos Industry and its Fight for Survival. Oxford: Oxford, 2008.

MENDES, René. Asbesto (amianto) e doença: revisão do conhecimento científico e fundamentação para uma urgente mudança da atual política brasileira sobre a questão. Cad. Saúde Pública, Rio de Janeiro, 17(1):7-29, jan-fev, 2001.

MORRISON, Wayne. Criminology, Civilisation and the New World Order. New York: Routledge, 2006.

MUNCIE, John. Decriminalising Criminology. The British Criminology Conference: Selected Proceedings. v. 3. Papers from the British Society of Criminology Conference, Liverpool, July 1999. Editors: George Mair and Roger Tarling.

NATALI, Lorenzo. Green criminology: Prostettive emergenti sui crimini ambientali. Torino: G. Giapichelli, 2015.

NOGUEIRA, D. P. Asbestose no Brasil: um risco ignorado. Revista de Saúde Pública, São Paulo, n. 9, p. 427-32, 1975.

OLIVEIRA, Cida de. Sem ser discutida, norma técnica do amianto segue inalterada. Rede Brasil Atual, 3 set. 2015. Disponível em: <http://www.redebrasilatual.com.br/saude/2015/09/norma-tecnica-do-amianto-segueinalterada-depois-de-comissao-adiar-discussao-777.html>. Acesso em: 5 set. 2015.

REIMAN, Jeffrey. The Rich Get Richer and the Poor Get Prison: Ideology, Class, and Criminal Justice. $8^{\text {th }}$ ed. New York: Pearson, 2007.

RUFF, Kathleen. Exporting Harm: How Canada Markets Asbestos to the Developing World. Ottawa: Rideau Institute, 2008.

RUGGIERO, Vincenzo. It's the economy, stupid! Classifying power crimes. International Journal of the Sociology of Law, 35 (2007) 163 - 177.

RUGGIERO, Vincenzo. Justifying the crimes of the powerful. In: BARAK, Gregg (ed.). The Routledge International Handbook of the Crimes of the Powerful. New York: Routledge, 2015. p. 62-72.

SANTOS, Juarez Cirino. A criminologia radical. Rio de Janeiro: Forense, 1981.

SCHWENDINGER, Herman; SCHWENDINGER, Julia. Defensores da ordem ou guardiães dos direitos humanos? In: TAYLOR, Ian; WALTON, Paul; YOUNG, Jock. Criminologia crítica. Rio de janeiro: Gral, 1980. p.113-134. 
STAYNER, L. T.; DANKOVIC, D. A.; LEMEN, R. A. Occupational exposure to chrysotile asbestos and cancer risk: a review of the amphibole hypothesis. American Journal of Public Health. 1996, Feb, v. 86, n. 2, p. 179-86. Disponível em:

<http://www.ncbi.nlm.nih.gov/pubmed/8633733>. Acesso em: 25 ago. 2015.

SUTHERLAND, Edwin H. White Collar Criminality, American Sociological Review, v. 5, n. 1, Feb. 1940, p. 1-12. Available in: <http://www.jstor.org/stable/2083937>. Acessed in: 31 mar. 2010.

WORLD HEALTH ORGANIZATION. Asbestos: elimination of asbestos-related diseases. Disponível em:

<http://apps.who.int/iris/bitstream/10665/69479/1/WHO_SDE_OEH_06.03_eng.pdf>. Acesso em: 03 mar. 2015.

ZAFFARONI, Eugenio Raúl. Criminología: aproximación desde un margen. Bogotá: Temis, 1988.

ZAFFARONI, Eugenio Raúl. El crimen de Estado como objeto de la criminología. In: GARCÍA RAMÍREZ, Sergio; ISLAS DE GONZÁLEZ MARISCAL, Olga. Panorama internacional sobre justicia penal: Política criminal, derecho penal y criminología. Culturas y sistemas jurídicos comparados. Séptimas Jornadas sobre Justicia Penal. México D.F.: UNAM, 2007.

ZAFFARONI, Eugenio Raúl. Em busca das penas perdidas: o sistema penal em questão. Rio de Janeiro: Revan, 1991. 